\title{
Neural-Network Vector Controller for Permanent-Magnet Synchronous Motor Drives: Simulated and Hardware- Validated Results
}

\begin{abstract}
This paper focuses on current control in a permanentmagnet synchronous motor (PMSM). The paper has two main objectives: The first objective is to develop a neural-network (NN) vector controller to overcome the decoupling inaccuracy problem associated with conventional PI-based vector-control methods. The NN is developed using the full dynamic equation of a PMSM, and trained to implement optimal control based on approximate dynamic programming. The second objective is to evaluate the robust and adaptive performance of the $\mathrm{NN}$ controller against that of the conventional standard vector controller under motor parameter variation and dynamic control conditions by (a) simulating the behavior of a PMSM typically used in realistic electric vehicle applications and (b) building an experimental system for hardware validation as well as combined hardware and simulation evaluation. The results demonstrate that the NN controller outperforms conventional vector controllers in both simulation and hardware implementation.
\end{abstract}

Index Terms - approximate dynamic programming, neural network, permanent-magnet synchronous motor, vector control, voltage source inverter

\section{INTRODUCTION}

$\mathbf{T}$ HE performance of a PMSM depends not only on its hardware design, but also on how it is controlled. Motor current control plays a particularly critical role [1]. Since there is a direct relation between motor current and torque, current control is equivalent to torque control [2]. To achieve fast and accurate current or toque tracking, several improved control techniques have been developed recently, including: predictive current control $[1,2]$, direct torque control [3,4], proportional-integral (PI) plus proportionalresonant (PR) control [5], and mixed $\mathrm{H} 2 / \mathrm{H} \infty$ control [6].

Predictive current control $[1,2]$ uses a current-prediction equation to estimate the motor current at the next sampling interval and a control equation to determine the next control action. It shows fast current-tracking response but becomes unstable when the actual motor's parameters differ from the programmed parameters used in the predictive controller [2].

Direct torque control has gained popularity in PMSM drives by providing a simple implementation for instant motor torque and stator-flux control [4]. However, it suffers from drawbacks: variable switching frequency, large torque ripple, and high sampling rates for digital implementation [4].

PI-PR control is similar to the conventional standard fieldoriented vector control, except that it combines PI with several PR control paths to enhance tracking of the current reference which may contain a lot of AC disturbance components [5]. The PI-PR approach requires properly tuning parameters of different resonant terms, and its performance can be adversely affected when motor parameters change, or when disturbance harmonics are different from those used to tune the resonant terms.
The mixed $\mathrm{H} 2 / \mathrm{H} \infty$ control method [7] has become popular [8]-[10]. However, it requires a reasonably accurate system model [11]. Also, it does not handle non-linear constraints very well [11]. In [12], it was found that applying a mixed $\mathrm{H} 2 / \mathrm{H} \infty$ controller in experimental conditions is much more challenging than in simulated environments.

As a result of these weaknesses, the conventional standard field-oriented vector control is still the dominant motorcurrent control strategy for PMSMs in today's motor drive industry $[13,14]$. But, recent studies show this conventional control strategy is inherently limited [15].

Neural networks (NNs) have been applied in PMSM control since the 1990s. But, to the best of our knowledge, NNs have not been used for current control of a PMSM based on a voltage source inverter (VSI). In [16], a feedforward NN identifier is utilized to replace the traditional speed-loop controller to generate a reference current. The reference current is then compared with the actual current to drive a current source inverter (CSI) through a hysteresis switching scheme. The NNs presented in [17] and [18] have a similar function to the NN used in [16]. The difference is that a typical current-loop controller is introduced after the NN identifier, and VSI replaces a CSI as the PMSM inverter. In [19], a feedforward NN is used as an identifier for a PMSM for the purpose of offsetting the impact of uncertainties.

This paper develops a novel control strategy: NN-based current vector-controller for a PMSM trained using an Approximate Dynamic Programming (ADP) method. In recent years, significant research has been conducted in optimal control of nonlinear systems based on ADP [20-23], none of which however focuses on vector control of PMSM motors in power applications, although many recent studies have pivoted around developing ADP techniques for optimal energy management in a time scale from several minutes to several hours. These include ADP-based optimal energy storage management with solar renewable [24], ADP-based optimal battery management for residential energy systems [25], and ADP-based optimal home energy management [26]. But, the focus of this paper is on real-time control of PMSMs for a time scale of milliseconds and below. In [27], a preliminary $\mathrm{NN}$ vector control structure for PMSMs was developed.

This paper has extended far beyond [27]. The special contributions of the paper include: (a) an ADP-based NN controller, (b) training of the NN as a recurrent network, (c) detailed stability evaluation under a wide range of diverse conditions and parameter uncertainties, (d) implementation and hardware experiment testing of the NN controller.

Several important features of the proposed NN control method include:

1) The NN is trained as a recurrent network, which enables it to exhibit fixed-weight adaptive behavior [28], and 
predictive control ability, like conventional current-predictive controllers.

2) The NN is trained to optimize an ADP-based cost function, making the $\mathrm{NN}$ controller an approximate optimal controller, like an $\mathrm{H} 2 / \mathrm{H} \infty$ controller.

3) The NN controller takes the error integral information as the input, which guarantees that no steady-state error exists for the reference tracking.

4) The NN can, in theory, emulate PI-PR control features, due to the universal function-approximation capability of NNs.

Thus, the NN has the potential to integrate optimal, predictive, PI, and PR control characteristics into one controller. This paper demonstrates the NN controller's improved performance, under both simulation and hardware conditions as compared to the conventional control methods.

It is worth emphasizing that the $\mathrm{NN}$ controller is trained entirely offline under a wide range of simulated circumstances, which allows our NN controller to adapt and respond to changing motor parameters in real time [28]. This leads to three further key benefits of our method:

a) The controller shows sufficient adaptive ability not to need retuning every time the motor's hardware parameters change slightly.

b) The computational cost at runtime is extremely low and easy to implement in low-cost hardware.

c) As training is completed offline, it is not possible for the weights of the NN to destabilize at runtime.

The trained NN controller's stability for controlling the PMSM at runtime is validated against a test set and a hardware experiment. The test set is intended to cover a sufficiently wide range of circumstances to empirically provide evidence for the stability of the controller. A formal proof of runtime stability is not provided. Such proof would involve the development of an analytical framework that is beyond the scope of this paper.

The rest of the paper is structured as follows: Section II covers the basic equations of the PMSM and conventional field-oriented control. Section III elaborates on the NN control method. Section IV shows how to train an NN based on ADP to implement vector control for a PMSM. Section V shows how to integrate NN control in a nested-loop PMSM control configuration. Sections VI and VII compare the performance of conventional and NN vector-control schemes through computer simulation and hardware experiments. Finally, the paper concludes with a summary of the main points.

\section{COnVentional Vector CONTROL}

\section{A. PMSM Model}

Conventional field-oriented vector control is based on the Park transformation. Using the motor sign convention, this yields the stator voltage equation [29] as:

$$
\left(\begin{array}{c}
v_{s d} \\
v_{s q}
\end{array}\right)=\left(\begin{array}{cc}
R_{s}+L_{d} \cdot d / d t & -\omega_{e} L_{q} \\
\omega_{e} L_{d} & R_{s}+L_{q} \cdot d / d t
\end{array}\right)\left(\begin{array}{c}
i_{s d} \\
i_{s q}
\end{array}\right)+\left(\begin{array}{c}
0 \\
\omega_{e} \psi_{f}
\end{array}\right)
$$

where $R_{s}$ is the resistance of the stator winding; $\omega_{e}$ is the motor electrical rotational speed; $v_{s d}, v_{s q}, i_{s d}$, and $i_{s q}$, are the $d$ and $q$ components of instant stator voltage and current; $L_{d}$ and $L_{q}$ are the stator and rotor $d$ - and q-axis inductances; and $\psi_{f}$ is the flux linkage produced by the permanent magnet (PM).
The torque balance equation of a PM motor [29] is:

$\tau_{e m}=J_{e q} d \omega_{m} / d t+B_{a} \omega_{m}+T_{L}$,

where $J_{e q}$ is the inertia of the motor; $\omega_{m}$ is the motor rotational speed; $B_{a}$ is the friction coefficient; $T_{L}$ is the load torque; and $\tau_{e m}$ is the electromagnetic drive torque. Depending on the type of a PMSM, a surface PM (SPM) or interior PM (IPM) motor, $\tau_{e m}$ can be expressed as follows:

$$
\begin{array}{ll}
\tau_{e m}=P\left(\psi_{f} i_{s q}\right) & \text { SPM motor } \\
\tau_{e m}=P\left(\psi_{f} i_{s q}+\left(L_{d}-L_{q}\right) i_{s d} i_{s q}\right) & \text { IPM Motor }
\end{array}
$$

in which $P$ represents the number of motor pole pairs. Lastly, the relation between $\omega_{m}$ and $\omega_{e}$ is given by:

$\omega_{e}=\omega_{m} \cdot P$

\section{B. Conventional PMSM Vector Control}

The conventional standard vector control technique usually has two distinctive nested-loop PI controllers: the outer speed and rotor flux linkage PI controllers and the inner current PI controllers as shown in Fig. 1 (top), where $\lambda_{r d}$ and $\lambda_{r d}{ }_{r d}$ represent actual and reference $d$-axis rotor flux linkages, respectively. The current-loop control strategy is developed by rewriting (1) as (5), where the terms in the large parentheses are used as the dynamic equations, and the other terms are compensation terms. These compensation terms are ignored when obtaining the system transfer functions $[29,30]$. Thus, the consequent transfer functions, $1 /\left(R_{S}+s \cdot L_{d}\right)$ and $1 /\left(R_{S}+s \cdot L_{q}\right)$, are used to tune a conventional $d$ - or $q$-axis PI controller. The omission of the compensation terms in deriving the transfer functions generates a decoupling inaccuracy. After the $d$ - and $q$-axis PI controllers are tuned, the compensation terms are added back to the output of the PI controllers, to form the final current-loop control configuration (Fig. 1 (top)).

$$
\begin{aligned}
& v_{s d}=\underbrace{\left(R_{s} i_{s d}+L_{d} d i_{s d} / d t\right)}_{v_{s d}^{\prime}}-\underbrace{\omega_{e} L_{q} i_{s q}}_{\text {Comp.Term }} \\
& v_{s q}=\underbrace{\left(R_{s} i_{s q}+L_{q} d i_{s q} / d t\right)}_{v_{s q}^{\prime}}+\underbrace{\omega_{e} L_{d} i_{s d}+\omega_{e} \psi_{f}}_{\text {Comp.Term }}
\end{aligned}
$$

The design of the speed-loop controller is based on the transfer function obtained from (2) and (3a), which is $\psi_{f} P /\left(B_{a}+s \cdot J_{e q}\right)$. Details about how to tune both current- and speed-loop controllers are presented in Section V.

\section{NN VECTOR CONTROL}

To address the decoupling inaccuracy associated with the conventional standard vector control, a novel NN controller is proposed to replace the PI-based current controller. The NN vector controller, known here as the action network, is implemented as shown in the lower right side of Fig. 1. The outer speed loop remains unchanged. The design stages of the $\mathrm{NN}$ controller are analogous to the design stages of a conventional controller. Firstly, like a conventional controller, a dynamic model of the plant is needed. Secondly, the NN structure needs to be specified which is analogous to specifying a conventional controller structure. Thirdly, the NN needs to be trained, which is analogous to tuning a conventional controller. 


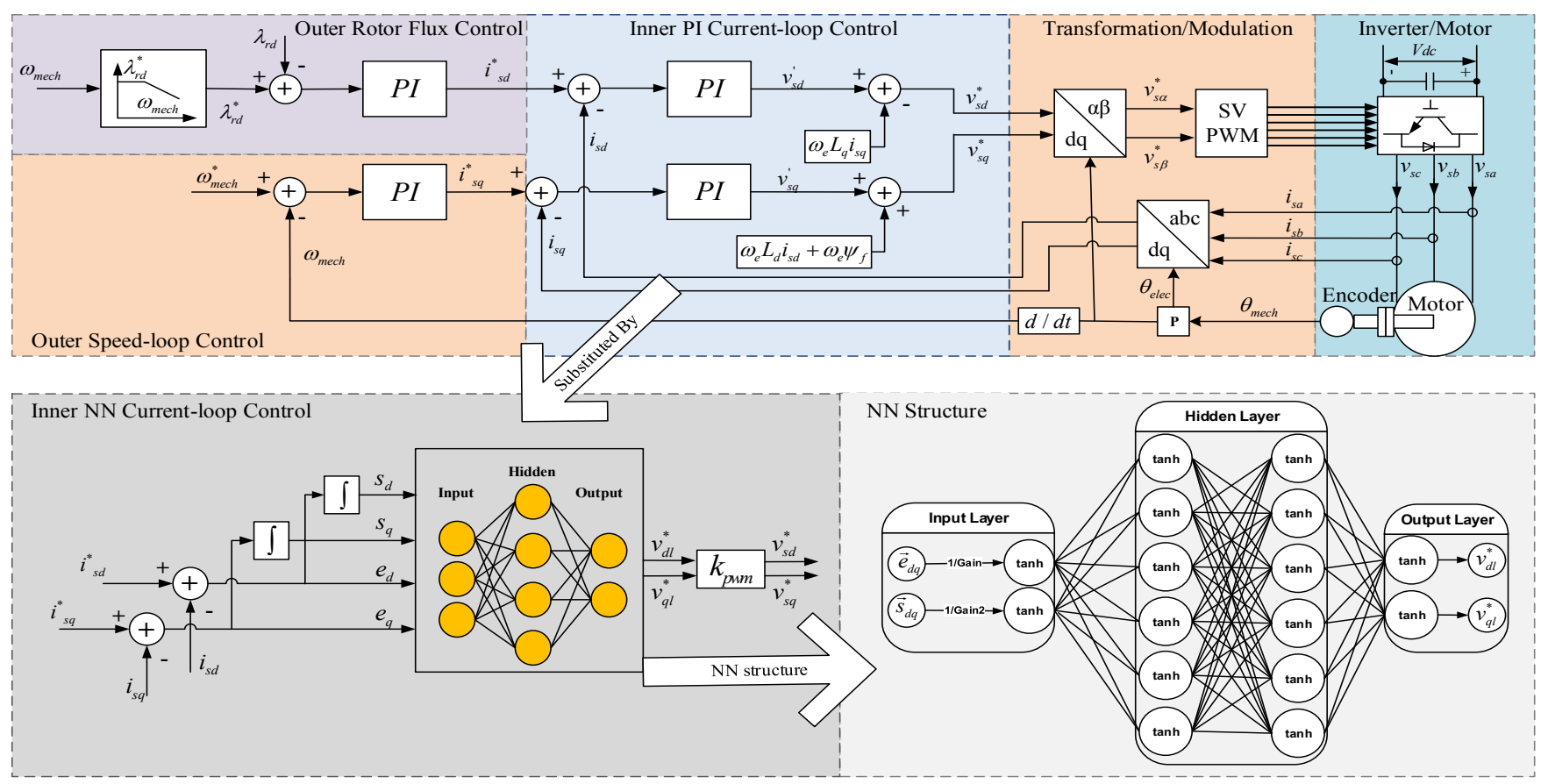

Fig. 1. PMSM conventional (top) and neural-network (highlighted in grey color) vector control

\section{A. State-Space Model of PMSM Current Loop}

The NN current vector controller is developed using a state-space model of the PMSM, by rearranging (5) into the standard state-space form, as shown by:

$\frac{d}{d t}\left(\begin{array}{c}i_{s d} \\ i_{s q}\end{array}\right)=-\left(\begin{array}{cc}R_{s} / L_{d} & -\omega_{e} L_{q} / L_{d} \\ \omega_{e} L_{d} / L_{q} & R_{s} / L_{q}\end{array}\right)\left(\begin{array}{l}i_{s d} \\ i_{s q}\end{array}\right)+\left(\begin{array}{c}v_{s d} / L_{d} \\ v_{s q} / L_{q}-\omega_{e} \psi_{f} / L_{q}\end{array}\right)(6)$

where the system states are $i_{s d}$ and $i_{s q}$. The PM flux $\psi_{f}$ is assumed to be constant, and the converter output voltages $v_{s d}$ and $v_{s q}$ are proportional to the control voltage generated by the action network [31].

Since the NN controller is a digital controller, a discrete equivalent of the continuous state-space model is required. This is obtained by a zero-order or first-order hold discrete equivalent mechanism. This transformation yields:

$\left(\begin{array}{l}i_{s d}\left(k T_{s}+T_{s}\right) \\ i_{s q}\left(k T_{s}+T_{s}\right)\end{array}\right)=\mathbf{A}\left(\begin{array}{c}i_{s d}\left(k T_{s}\right) \\ i_{s q}\left(k T_{s}\right)\end{array}\right)+\mathbf{B}\left(\begin{array}{c}v_{s d}\left(k T_{s}\right)-0 \\ v_{s q}\left(k T_{s}\right)-\omega_{e} \psi_{f}\end{array}\right)$

in which $T_{s}$ is the sampling period, $\mathbf{A}$ is the system matrix, and B is the input matrix. Since $T_{s}$ is present on both sides, (7) can be simplified as:

$\vec{i}_{s d q}(k+1)=\mathbf{A} \cdot \vec{i}_{s d q}(k)+\mathbf{B} \cdot\left(\vec{v}_{s d q}(k)-\vec{v}_{r d q}\right)$,

where $k$ is an integer time step, $\vec{i}_{s d q}=\left(i_{s d}, i_{s q}\right)^{T}, \vec{v}_{s d q}=\left(v_{s d}, v_{s q}\right)^{T}$ is the control action, and $\vec{v}_{r l q}=\left(0, \omega_{e} \psi_{f}\right)^{T}$ represents the induced voltage of the permanent magnet.

\section{B. NN Structure}

The NN has a feedforward network structure as shown in the lower right side of Fig. 1. It consists of four different layers: an input layer, two hidden layers, and an output layer. The input layer contains four inputs. Two of these inputs comprise the vector $\vec{e}_{d q}(k)$, the error term, and the other two comprise $\vec{S}_{d q}(k)$, the integral of the error term. These two terms are defined by:

$\vec{e}_{d q}(k)=\vec{i}_{s d q}(k)-\vec{i}_{s d q}^{*}(k), \vec{s}_{d q}(k)=\vec{s}_{d q}(k-1)+\vec{e}_{d q}(k) \cdot T_{s}$,

where $\vec{i}_{s d q}^{*}(k)$ is the reference $d q$ current and $\vec{s}_{d q}(k)$ is the discrete integral of the error term obtained by the forward rectangle rule. We also investigated NNs with more hidden layers and more nodes in each hidden layer - but no major improvement was found.

As shown by (9), the NN has the same input signals, error terms and integrals of error terms, and same output signals as those used in a conventional PI controller. Hence, the NNbased controller can be considered as a "super-PI" controller, which can be conveniently applied to an existing PMSM digital control system for a more stable and reliable operation. The four inputs to the NN are first divided by their appropriate gains, and then processed through a hyperbolic tangent function, as shown in Fig. 1. The input layer then feeds into the hidden layers, each of which contains six nodes. Each node uses a hyperbolic-tangent activation function. Finally, the output layer gives $\vec{v}_{s d q}^{*}(k)$, the output of the NN. This output is multiplied by a gain, $k_{P W M}$, which represents the pulse-width-modulation (PWM) [29, 31], to obtain the final control action applied to the PMSM, $\vec{v}_{s d q}$, given by:

$\vec{v}_{s d q}(k)=k_{P W M} \cdot A\left(\vec{e}_{d q}(k), \vec{s}_{d q}(k), \vec{w}\right)$,

where $\vec{w}$ is the network's overall weight vector, and $A\left(\vec{e}_{d q}(k), \vec{s}_{d q}(k), \vec{w}\right)$ denotes the whole action network. The division of the inputs by Gain and Gain2 in the NN input layer is to avoid the input saturation [32]. A two-hidden-layer NN was selected because it generally yields a stronger 
approximation ability [33] than a one-hidden-layer NN and the training of a two-hidden-layer network is relatively easy compared with that for an NN with three or more hidden layers. The number of nodes in each hidden layer was selected via the trial-and-error method.

\section{TRAINING THE NN TO CONTROL THE PMSM}

\section{A. ADP-Based Control Formulation for a PMSM}

ADP is a very useful tool for solving and approximating an optimal control of a dynamic system [34]. A typical ADPbased control problem consists of a cost function and a mechanism that can minimize the cost function to achieve the ADP-based control. The cost function is used to measure the performance of the ADP-based control in tracking a target trajectory and is typically defined as [34]:

$$
C(\vec{x}(j), j)=\sum_{k=j}^{N} \gamma^{k-j} \cdot U(\vec{x}(k), \vec{u}(k), k)
$$

where $N$ is the trajectory length, $\gamma$ is the discount factor $(0 \leq \gamma$ $\leq 1), \vec{x}(k)$ signifies the states of a dynamic system, $\vec{u}(k)$ denotes the control action applied to the system, and $U(\bullet)$ is the utility function. The cost function $J(\bullet)$, dependent upon the initial time $j$ and the initial state $\vec{x}(j)$, is referred to as the cost-to-go of state $\vec{x}(j)$ in an ADP problem.

For vector control of a PMSM, the system states are $\vec{i}_{s d q}(k)$ and the control action is $\vec{v}_{s d q}(k)$ according to Section III. The goal of the current control for a PMSM is to be able to track any specified target reference current trajectory $\vec{i}_{s d q}^{*}(k)$ as close as possible. Therefore, the utility function in (11) for the PMSM vector control problem is defined as

$$
U\left(\vec{i}_{s d q}, \vec{v}_{s d q}, k\right)=\sqrt{\left(i_{s d}(k)-i_{s d}^{*}(k)\right)^{2}+\left(i_{s q}(k)-i_{s q}^{*}(k)\right)^{2}}
$$

In this paper, we choose $\gamma=1$, which makes the cost-to-go function of the ADP-based PMSM control problem as

$$
C\left(\vec{i}_{s d q}, j\right)=\sum_{k=j}^{N} \sqrt{\left[i_{s d}(k)-i_{s d}^{*}(k)\right]^{2}+\left[i_{s q}(k)-i_{s q}^{*}(k)\right]^{2}}
$$

The objective of training the NN controller for a PMSM is to have the $\mathrm{NN}$ output control actions $\vec{v}_{s d q}(k)$, $k=j, j+1, \cdots, N$ so that the cost-to-go function $C(\bullet)$ of (13) is minimized. It is worth pointing out that although the control actions $\vec{v}_{s d q}(k)$ is not involved in (13), it affects (13) indirectly through (8). This impact is considered in the training of the $\mathrm{NN}$ as shown in the following section.

\section{B. NN Training Mechanism to Optimize the ADP-Based Cost Function}

The NN shown in Section III is trained to approximate optimal control by using gradient descent to adjust the weights of the action neural network until its outputs minimize (13). As shown in Fig. 1, the NN receives the $d q$ current feedback signal from the PMSM motor. Thus, the output control action of the NN at time step $k$ changes the output current of the
PMSM at time step $k+1$ via (7) or (8), the output motor current then changes NN inputs at time step $k+1$ via (9), and then the NN output control action at time step $k+1$ is modified via (10). This recursive process continues, making the combined system of the PMSM + NN similar to a recurrent neural network. This combined "recurrent network" is shown in Fig. 2, unrolled in time, illustrating how the PMSM and the NN interact with each other. The recurrence in this architecture needs to be fully considered when computing the gradient of the ADP cost function (11) so as to enable learning by the gradient descent [35]. Doing so allows the trained NN to gain strong multi-step-ahead predictive control ability that is much more powerful than the conventional predictive controllers.

Learning was accelerated using the Levenberg-Marquardt (LM) optimization method [36]. The LM algorithm has been widely used to train feedforward networks, and provides a nice compromise between the speed of Newton's method and the guaranteed convergence of the steepest descent. For a moderate number of network parameters or weights, LM appears to be one of the fastest neural network training algorithms. However, since the NN and PMSM are treated as a recurrent neural network, it is necessary to modify the LM algorithm slightly using the method detailed by [32] and summarized below.

First, the gradient of (13) is computed with respect to the weight vector $\partial C / \partial \vec{w}$. In matrix form this is:

$$
\frac{\partial C}{\partial \vec{w}}=\frac{\partial \sum_{k=1}^{N}(V(k))^{2}}{\partial \vec{w}}=\sum_{k=1}^{N} 2 V(k) \frac{\partial V(k)}{\partial \vec{w}}=2 J_{p}(\vec{w})^{T} V
$$

where $V(k)=\sqrt{U\left(\vec{i}_{s d q}, \vec{v}_{s d q}, k\right)}, V$ is a vector containing $\mathrm{V}(1)$ to $\mathrm{V}(\mathrm{N})$, and $J_{p}(\vec{w})$ is a Jacobian matrix defined for a recurrent neural-network by:

$$
J_{p}(\vec{w})=\left[\begin{array}{ccc}
\frac{\partial V(1)}{\partial w_{1}} & \cdots & \frac{\partial V(1)}{\partial w_{M}} \\
\vdots & \ddots & \vdots \\
\frac{\partial V(N)}{\partial w_{1}} & \cdots & \frac{\partial V(N)}{\partial w_{M}}
\end{array}\right], \quad V=\left[\begin{array}{c}
V(1) \\
\vdots \\
V(N)
\end{array}\right]
$$

Then, using these definitions, the weight update is applied as:

$$
\begin{aligned}
& \Delta \vec{w}=-\left[J_{p}(\vec{w})^{T} J_{p}(\vec{w})+\mu \mathbf{I}\right]^{-1} J_{p}(\vec{w})^{T} V \\
& \vec{w}_{\text {update }}=\vec{w}+\Delta \vec{w}
\end{aligned}
$$

where $\mathbf{I}$ is the identity matrix, and $\mu$ is a scalar that is dynamically adjusted by the LM algorithm [36].

As (14)-(16) show, the Jacobian matrix, $J_{p}(\vec{w})$, is the kernel for training used by the LM method. To efficiently compute the Jacobian matrix, we used a forward accumulation through time (FATT) algorithm, described in detail by [32]. FATT is analogous to the better-known back-propagation through time algorithm [37]; but with the differences that FATT accumulates its result via a forward-mode automatic differentiation [38], and also that FATT delivers a whole Jacobian matrix as opposed to a single gradient vector. Please 


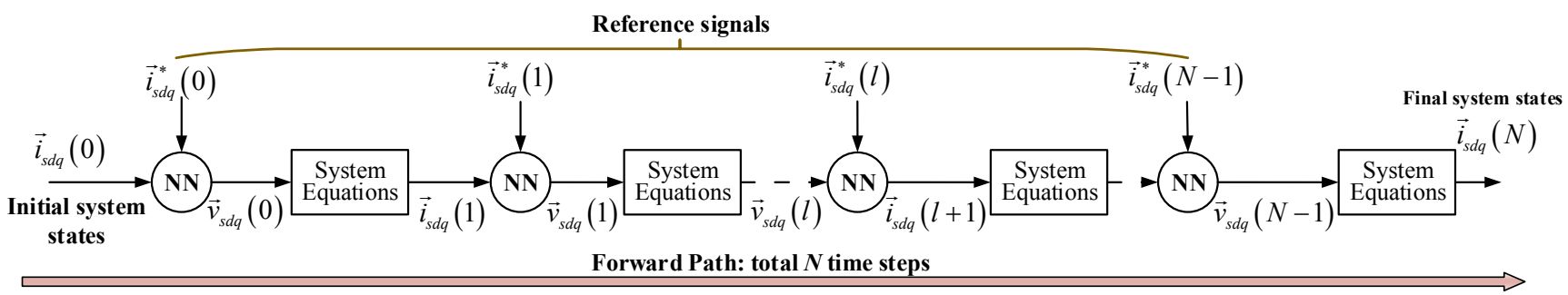

Fig. 2. Feedback loop between the NN and the PMSM (via the system equations (8), and via the neural inputs (9)). The combined PMSM+NN system is treated as a recurrent neural network, shown unrolled in time here.

note that the use of FATT, in this case, is chosen merely because it is slightly more computationally efficient than computing the Jacobian matrix by a backward accumulation, but gives exactly the same result subject to floating-point rounding errors. It should be emphasized that to correctly compute $J_{p}(\vec{w})$ by FATT, it is necessary to differentiate through the known motor model equations (8), and feed these derivatives into the next time step's neural inputs, via (9)-(10) and the chain-rule, and ultimately feed this chain of derivatives into the accumulating cost function (13), at each subsequent time step. Fuller details are given by [32].

\section{TRAINING/Tuning PMSM CURRENT- AND SPEED-LOOP CONTROLLERS FOR SiMULATION AND HARDWARE CASES}

The PMSM nested-loop control has been considered in two SPM motor cases: one for simulation and one for a hardware experiment. The simulation case uses parameters of a PM motor that are typical for an electric vehicle application [39]. The hardware experiment is based on a laboratory PM motor [40], which has a smaller power rating and is mainly used for the purpose of experimental validation. Table I shows the PM motor parameters used in each case.

TABLE I

PMSM DATA USED IN SIMULATION/EXPERIMENTAL STUDY

\begin{tabular}{|c|c|c|c|c|}
\hline & Parameter & Simulation & Hardware & Units \\
\hline \multirow{11}{*}{$\begin{array}{l}\overrightarrow{0} \\
\stackrel{0}{c}\end{array}$} & Rated Power & 50 & 0.24 & $\mathrm{~kW}$ \\
\hline & Nominal Speed & 1200 & 2800 & RPM \\
\hline & Nominal Torque & 250 & 1.5 & $\mathrm{~N} \cdot \mathrm{m}$ \\
\hline & Maximum Speed & 6000 & 3800 & RPM \\
\hline & Permanent magnet flux & 0.1758 & 0.01544 & $\mathrm{~Wb}$ \\
\hline & Inductance in $q$-axis, $\mathrm{L}_{\mathrm{q}}$ & 1.598 & 0.255 & $\mathrm{mH}$ \\
\hline & Inductance in d-axis, $\mathrm{L}_{\mathrm{d}}$ & 1.598 & 0.255 & $\mathrm{mH}$ \\
\hline & Stator copper resistance, $\mathrm{R}_{\mathrm{s}}$ & 0.0065 & 0.22 & $\Omega$ \\
\hline & Inertia & 0.089 & 0.0004 & $\mathrm{~kg} \cdot \mathrm{m}^{2}$ \\
\hline & Friction coefficient & 0.1 & 0.001 & $\mathrm{~N} \cdot \mathrm{m} \cdot \mathrm{s} / \mathrm{rad}$ \\
\hline & Pole pairs & 4 & 4 & 2 \\
\hline \multirow{3}{*}{$\begin{array}{l}\overrightarrow{\vec{\omega}} \\
\overrightarrow{0} \\
\vec{\Xi}\end{array}$} & Inverter rating & 60 & 0.4 & $\mathrm{kVA}$ \\
\hline & dc voltage & 500 & 42 & $\mathrm{~V}$ \\
\hline & Switching frequency & 6 & 10 & $\mathrm{kHz}$ \\
\hline
\end{tabular}

\section{A. Tuning Speed-loop Controller}

The PI parameters of the speed-loop controller are tuned using the proportional-integral-derivative (PID) tuner function within the PID controller block in MATLAB. Fig. 3 shows the closed-loop Simulink model used to tune the speed-loop PI parameters. The transfer function in Fig. 3 is $\psi_{f} P /\left(B_{a}+s \cdot J_{e q}\right)$ (derived from (2) and (3a) in Section II-A), where $B_{a}$ was set to zero. The phase margin was 60 degrees, while the controller bandwidth in terms of angular frequency was chosen as 200 $\mathrm{rad} / \mathrm{s}$. Then, the PI gains were adjusted until a better speed tracking performance is achieved. Note that both the $\mathrm{NN}$ and conventional controllers use the same speed-loop PI gains.

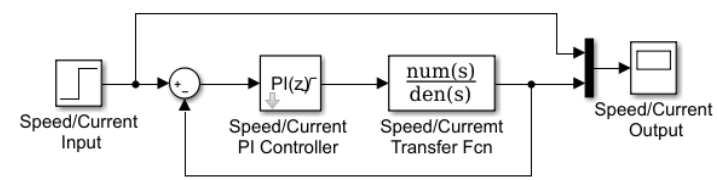

Fig. 3. Using Simulink to design the speed- and current-loop controllers

\section{B. Tuning Conventional Current-loop Controller}

The PI gains of the conventional current-loop controller were also tuned using the PID tuner function. The transfer function in Fig. 3 is $1 /\left(R_{S}+s \cdot L_{d}\right)$ or $1 /\left(R_{S}+s \cdot L_{q}\right)$ (see Section II$B)$. The current controller bandwidth in terms of angular frequency was $2,000 \mathrm{rad} / \mathrm{s}$ while the phase margin was kept the same as that of the speed-loop controller. Since the current controller is in the inner loop, the bandwidth has to be larger to track the current well. Similarly, the PI gains were then adjusted until a better tracking performance was obtained.

\section{Training NNS}

For both the simulation and hardware experimental cases, an NN was trained using the method of Section IV and the motor parameters of Table I. The training procedure is as follows: 1) randomly generate changing sample reference $d q$ current trajectories; 2) randomly generate a sample initial state $\left.i_{s d q}(1) ; 3\right)$ unroll the PMSM current trajectory from the initial state; 4) train the NN as detailed in Section IV; and 5) repeat the process for all of the reference $d q$ current trajectories and sample initial states until reaching a stop criterion. Each initial state $i_{s d q}(1)$ was generated randomly within acceptable $d$ - and $q$-axis current ranges that are within the rated current limit in terms of the current amplitude and also cannot cause the controller to operate beyond the PWM saturation limit, i.e.,

$\sqrt{I_{s d}^{2}+I_{s q}^{2}} \leq I_{s d q_{-} \text {rated }}, \quad \sqrt{V_{s d}^{2}+V_{s q}^{2}} \leq V_{s d q_{-} \max }$

where $I_{s d q_{-} \text {rated }}$ and $V_{s d q_{-} \max }$ denote the rated motor $d q$ current amplitude and maximum $d q$ voltage amplitude that can be applied to the motor due to the motor inverter PWM saturation constraint, respectively. Each trajectory duration was unrolled for a duration of 1 second, with a sampling time of $T_{s}=0.1 \mathrm{~ms}$, and the reference $d q$ current was changed randomly every 0.1 seconds also within acceptable $d$ - and q-axis current ranges. All of the network weights were initially randomized using a uniform distribution within \pm 0.1 , and 10 randomized reference current trajectories were created during each training epoch. Fig. 4 shows a successful training convergence obtained through the use of the LM algorithm. Note that the $\mathrm{NN}$ is 
trained offline, and no training occurs in the real-time control stage. After training, the $\mathrm{NN}$ controller is intended to be able to optimally track the reference $d$ - and $q$-axis currents.

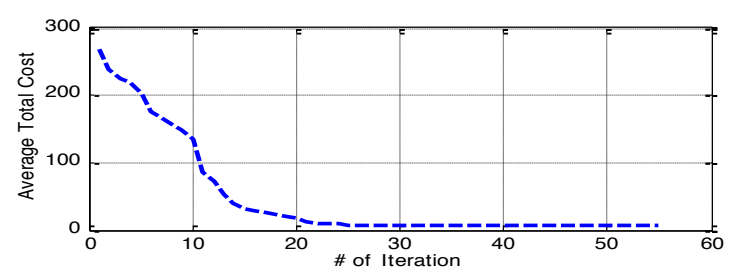

Fig. 4. Average cost per trajectory time step for training NN

\section{Performance and Stability Evaluation of CONVENTIONAL AND NN VECTOR CONTROLLERS USING SIMPOWERSYSTEMS}

A simulation model of the PM motor drive was developed using MATLAB SimPowerSystems based on parameters of the simulated PMSM in Table I. Fig. 5 shows the simulation model containing conventional and NN controllers as shown in Fig. 1. The controller sampling rate is $0.1 \mathrm{~ms}$. Details about how to build a simulation model using SimPowerSystems can be found in [41]. In the MATLAB environment, the computing time for each control action of the NN takes about $20 \mu \mathrm{s}$. Since the NN is trained offline, no training occurs in the real-time control stage, which makes the $\mathrm{NN}$ control algorithm very fast to execute. This execution time will reduce further when the NN is implemented on a DSP chip.

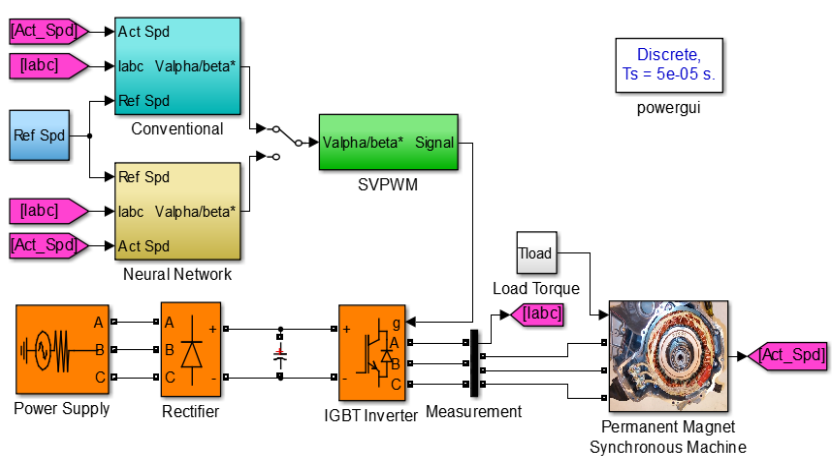

Fig. 5. PMSM motor control configuration in SimPowerSystems

The stability of the NN was evaluated against a testing dataset, as is a common practice in the neural network field [42]. The training and testing datasets represent different sets of trajectories. The testing dataset covers an extremely wide range of circumstances to validate the $\mathrm{NN}$ controller over various key criteria. These criteria include speed-control, current control, robustness of speed- and current-loop control, robustness against fluctuations in flux-linkage, robustness against load disturbance, and improved tolerance to sampling time variations, etc., as shown in Sections VI-A to VI-G.

\section{A. Speed Control Evaluation}

Fig. 6 compares motor speed control using conventional and NN control techniques, in which the friction factor and the load torque are zero. The motor starts with a reference rotational speed increasing linearly from $0 \mathrm{rad} / \mathrm{s}$ to $60 \mathrm{rad} / \mathrm{s}$, stays at $60 \mathrm{rad} / \mathrm{s}$ for about 0.75 seconds, and then reduces to $40 \mathrm{rad} / \mathrm{s}$. At $\mathrm{t}=2 \mathrm{~s}$, the reference speed increases to $80 \mathrm{rad} / \mathrm{s}$, and then remains at $80 \mathrm{rad} / \mathrm{s}$. The reference $d$-axis current is
0A. Both the conventional and $\mathrm{NN}$ controllers can track the reference speed properly. But, for each reference speed increase or decrease, the conventional controller shows more overshoot and oscillations, particularly in motor current (Fig. $6 \mathrm{~b} \& 6 \mathrm{c})$, implying that there are more torque oscillations when using the conventional controller. Note: the reference $q$ axis current is generated by the speed-loop controller as shown in Fig. 1.

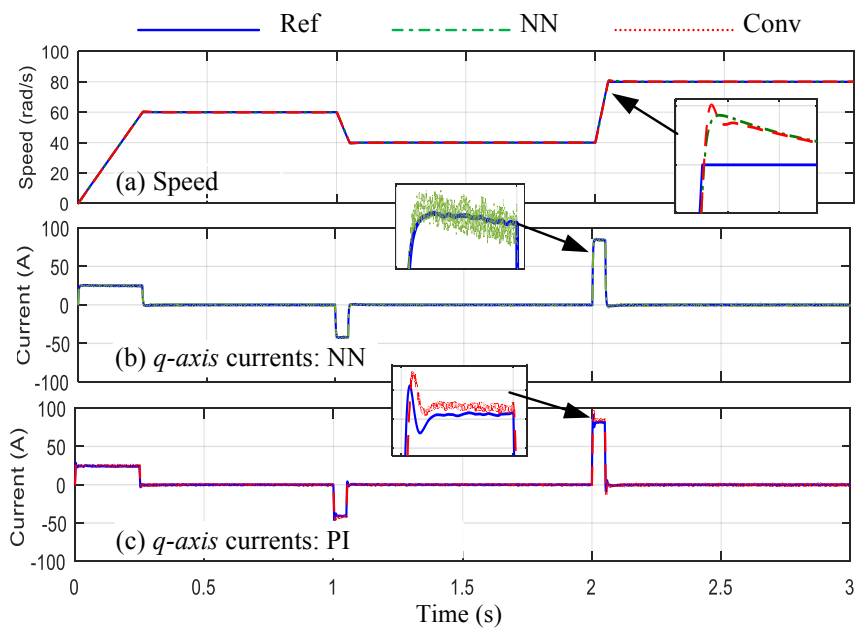

Fig. 6. Speed tracking control - NN vs. conventional: (a) motor rotational speeds, (b) reference/actual q-axis currents using NN control, (c) reference/actual $q$-axis currents using conventional control.

\section{B. Current Control Evaluation}

In the motor drive industry, evaluation of the current-loop controllers is normally conducted under the condition that the speed of the test motor is kept constant and the motor is evaluated while tracking reference $d$ - and q-axis currents. This can be achieved, as in Fig. 5, by changing Load Torque block to Speed block and setting the PMSM to operate according to a specified constant speed value. Fig. 7 compares currentcontrol performance using conventional and NN controllers. The initial $d$-axis reference current is $-40 \mathrm{~A}$ and changes to $-80 \mathrm{~A}$ at $0.4 \mathrm{~s}$. The initial $q$-axis reference current is $100 \mathrm{~A}$ and changes to $0 \mathrm{~A}$ at $0.25 \mathrm{~s}$ and then to $50 \mathrm{~A}$ at $0.6 \mathrm{~s}$. As shown in Fig. 7, the $\mathrm{NN}$ controller is more stable and reliable, and responds faster than the conventional controller.

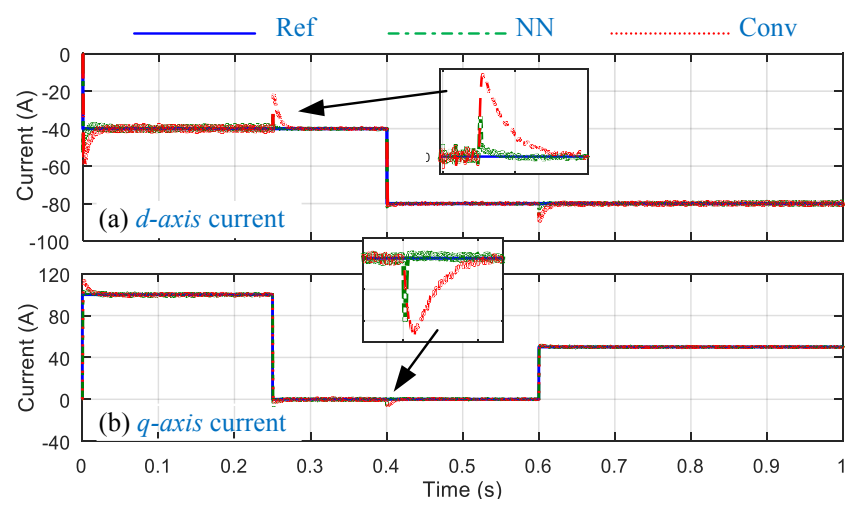

Fig. 7. Current tracking control - NN vs. conventional: (a) d-axis current, (b) $q$-axis current.

\section{Robustness of Speed-Loop Controller}

In practical applications, both the motor inertia and friction factor may change depending on the load of the EV and road 
(96) speed-loop controller (Fig. 8 compares conventional and NN vector-control methods when the friction factor changes from $0 \mathrm{~N} \cdot \mathrm{m} \cdot \mathrm{s}$ in Fig. 6 to $0.2 \mathrm{~N} \cdot \mathrm{m} \cdot \mathrm{s}$ and the inertia is tripled, while (c2) the other conditions are the same as those used in Fig. 6, except that a load torque of $20 \mathrm{~N} \cdot \mathrm{m}$ is included. In general, the speed tracking control is not affected much and shows a similar performance using both $\mathrm{NN}$ and conventional vector controllers. Compared to Fig. 6, a little more time is needed for the transition from one reference speed to another, due to a larger inertia and friction factor.

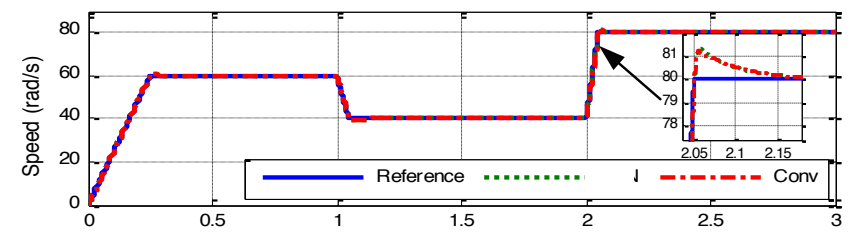

Fig. 8. NN vs. conventional: Reference and actual motor rotational speeds for a higher motor inertia and friction factor

\section{Robustness of Current-Loop Controller}

In real applications, the motor resistance and inductance may deviate from their nominal values by a significant amount. This affects the PM motor current-loop controllers. Fig. 9 demonstrates what happens when both the motor resistance and inductance are reduced by $40 \%$, with all other conditions being the same as those used in Fig. 7. The results show the $\mathrm{NN}$ controller is better able to track the reference and actual $d$ and q-axis motor currents under variable parameter conditions, and is more stable and reliable than the conventional control.

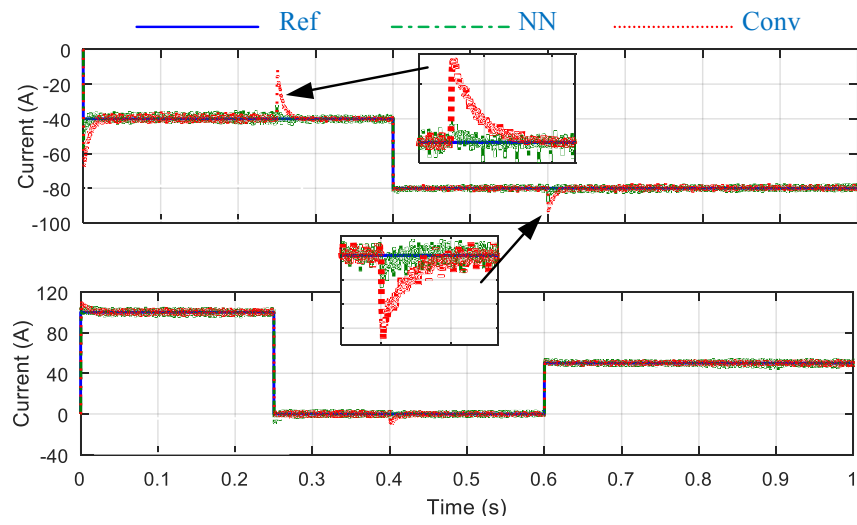

Fig. 9. NN vs. conventional for $40 \%$ decrease of motor resistance/inductance:



Fig. 10. NN vs. conventional for $40 \%$ increase of rotor flux linkage

\section{E. Impact of Rotor Magnet Flux Linkage}

In a PM motor, the rotor-magnet flux linkage may change due to an increase or decrease in the motor temperature. This would affect the performance of the motor. A test was carried out to evaluate the conventional and $\mathrm{NN}$ vector-control methods when the rotor magnet flux linkage is lower or higher than the nominal value listed in Table I. Fig. 10 compares current tracking using the conventional and NN control methods, when the rotor magnet flux linkage increases by $40 \%$, while the other conditions remain the same as those used in Fig. 7. The study shows a better dynamic response of $d$ - and q-axis current tracking using the $\mathrm{NN}$ controller.

\section{F. Impact of Load Disturbance and Sampling Rate}

Load disturbance and sampling rate impacts to motor speed control were also investigated. Fig. 11a shows PM motor performance, using conventional and NN controllers, under an impulse load disturbance while the other conditions are the same as those used in Fig. 6. The impulse disturbance of an additional $30 \mathrm{~N} \cdot \mathrm{m}$ appears at $1.5 \mathrm{~s}$ and lasts for $0.1 \mathrm{~s}$. Fig. $11 \mathrm{~b}$ shows the motor performance when a large sampling interval of $2 \mathrm{~ms}$ is applied to the speed-loop controller and to read motor position/speed data while the other conditions are the same as those used in Fig. 11a. The sampling time for the current-loop controller is still $0.1 \mathrm{~ms}$ as the motor current change is much faster than the speed change. The results show that the NN controller is less impacted by load disturbance and more reliable for a large sampling interval applied to the speed control loop than the conventional one.

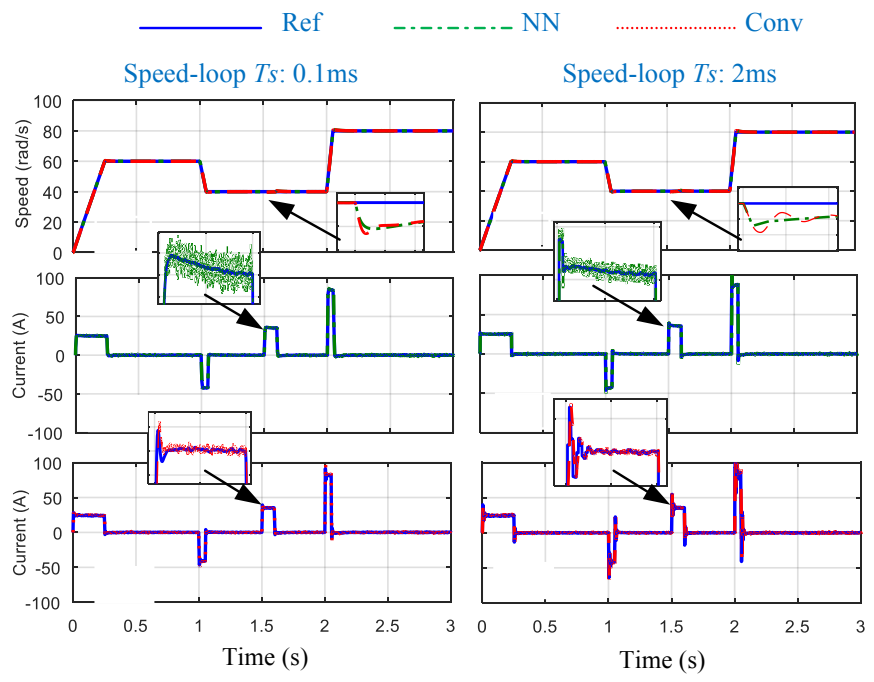

Fig. 11. NN vs. conventional - Load disturbance and speed-loop sampling time impacts: (a1)\&(b1) reference/actual motor rotational speeds, (a2)\&(b2) reference/actual q-axis currents using NN control, (a3)\&(b3) reference/actual q-axis currents using conventional PI control

A summary in terms of maximum, average, and standard deviation of the absolute tracking errors associated with Figs. 6 to 11 for the NN and conventional controllers is presented in Table II as shown below.

TABLE II

TRACKING ERROR MAXIMUM, AVERAGE, AND STANDARD DEVIATION VALUES

\begin{tabular}{|l|l|l|l|l|l|l|l|}
\hline \multirow{2}{*}{ Figure \# } & \multicolumn{2}{|c|}{ Maximum } & \multicolumn{2}{|c|}{ Average } & \multicolumn{2}{|c|}{ Std } \\
\cline { 3 - 7 } & NN & Conv. & NN & Conv. & NN & Conv. \\
\hline
\end{tabular}


NWN

\begin{tabular}{|c|c|c|c|c|c|c|c|}
\hline \multirow{4}{*}{ 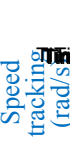 } & Fig. 6(a) & 1,3031 & 1.5132 & 0.0594 & 0.0586 & 0.1620 & 0.1585 \\
\hline & (f)ig. 8 & 3.5608 & 3.5610 & 0.18 finge & (s) 0.1851 & 0.4905 & 0.4901 \\
\hline & \begin{tabular}{|l|} 
Fig. 11(a1) \\
\end{tabular} & 1.3030 & 1.5133 & 0.0763 & 0.0755 & 0.1708 & 0.1676 \\
\hline & Fig. 11(b1) & 1.7839 & 2.1820 & 0.0797 & 0.0790 & 0.1836 & 0.1862 \\
\hline \multirow{6}{*}{ 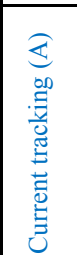 } & Fig. 7(a) & 24.53 & 29.90 & 0.54 & 0.79 & 0.57 & 1.41 \\
\hline & Fig. 7(b) & 99.25 & 99.58 & 0.79 & 0.86 & 1.65 & 1.71 \\
\hline & Fig. 9(a) & 17.24 & 24.81 & 0.93 & 1.05 & 0.78 & 1.88 \\
\hline & Fig. 9(b) & 99.66 & 100.13 & 1.70 & 1.65 & 1.73 & 1.71 \\
\hline & Fig. 10(a) & 22.36 & 28.83 & 0.64 & 0.84 & 0.59 & 1.40 \\
\hline & Fig. 10(b) & 99.77 & 99.86 & 1.19 & 1.18 & 1.68 & 1.73 \\
\hline
\end{tabular}

\section{G. Sampling Time Impact at High Speed}

The rotating speed of a PM motor is directly related to the electrical frequency of the stator voltage and current. As the rotating speed increases, the electrical frequency increases too. This requires the sampling rate to increase as the maximum demanded motor rotating speed increases. The study shows that for sampling times of $100,80,40$, and $20 \mu$ s, respectively, the NN controller can provide stable control in terms of rotational speed up to $10000,11000,13500$, and $16500 \mathrm{rpm}$, while the traditional controller crashes at 7500, 9000, 10000, and $13000 \mathrm{rpm}$, respectively. Fig. 12 shows the performance using conventional and NN controllers (including flux weakening control) for sampling times of $100 \mu \mathrm{s}$ and $20 \mu \mathrm{s}$, respectively. The study shows that the NN controller is more stable and reliable than the conventional controller in supporting the high-speed operation of a PM motor.


a1) Ref/actual motor rotational speed a2) Ref/actual motor rotational speed
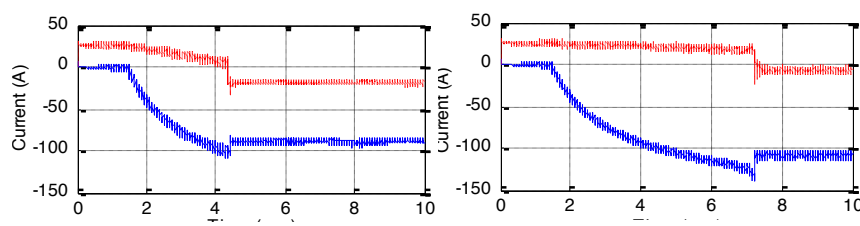

b1) $\mathrm{NN}$ : $d$ - and q-axis currents b2) NN: $d$ - and q-axis currents
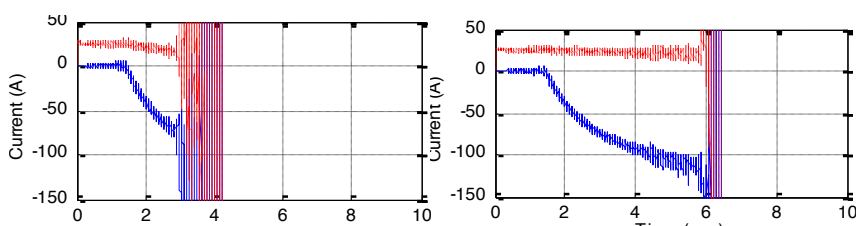

c1) Conv: $d$ - and q-axis currents

c2) Conv: $d$ - and q-axis currents

Fig. 12. NN vs. conventional: Sampling impact for PM motor control toward high rotational speed. The left and right column of graphs represent a sampling time of $100 \mu \mathrm{s}$ and $20 \mu \mathrm{s}$, respectively.

The stability of the PM motor control depends strongly on the $a b c$ to $d q$ transformation. This is especially true when the rotational speeds increase, which causes the rotor electrical angular position to change quickly. Thus, to capture the three- phase current and the electrical angular position information correctly, a small sampling time would be needed. Otherwise, the calculated $d q$ current can be distorted. Similar to Fig. 11, using the same sampling rate, the NN controller is more robust than the conventional controller at a high operating speed, as illustrated by Fig 12. A tentative explanation for this is that the $\mathrm{NN}$ is a comparatively flexible function approximator, compared to a PI or alternative controllers, and is specifically optimized to have a fast response time and low overshoot. On the other hand, the conventional PI-based controller only has two parameters to tune, and therefore cannot compete in fast response time and low overshoot. As a result, the NN controller has a stronger ability to compensate for the $d q$ transformation distortion caused by a low sampling rate than the conventional controller.

\section{HARDWARE EXPERIMENT}

\section{A. Experimental Setup}

To further verify the feasibility and stability of the NN vector controller, a DSP-based digital control system was implemented (Fig. 13). The experimental setup (Fig. 13(a)) consists of three major parts: (i) a motor drive system containing an SPM motor from Motorsolver coupled to a DC motor [40], (ii) a power converter board from Vishay HiRel Systems which has two independent three-leg converters, and (iii) a dSPACE DS1103 controller board to collect various input signals, e.g. current, voltage and motor speed, and to generate PWM output for controlling the SPM and DC motors. One converter was formed as a DC/AC converter to control the PM motor, while the other one was formed as an H-bridge $\mathrm{DC} / \mathrm{DC}$ converter to control the DC motor.

The control algorithms for both the PM and DC motors were built in Simulink (Fig. 13(b)). They were then compiled and loaded as the assembly code to the DSP chip within the DS1103 controller board. In Fig. 13(b), the measurements of the PM motor's speed and rotor position are obtained by the DS1103ENC POS module, and the voltage and current measurements are obtained by the DS1103ADC module. The speed measurements are passed to both the DC and PM motor controllers; the three-phase PM motor current measurements are passed to the PM motor controller; and the DC motor current measurement is passed to the DC motor controller.

The PM motor-controller block implements either the conventional or NN vector control, according to Fig. 1, and outputs the $\alpha$ and $\beta$ reference voltage to the space-vector modulation block, which generates $\mathrm{T} 1, \mathrm{~T} 2$, and sector information needed by the DS1103SL DSP PWMSV block to generate the driving pulses. The driving pulses are applied to the three-phase DC/AC converter to control the PMSM. The DC motor controller block generates two complementary duty ratio signals that are passed to DS1103SL_DSP_PWM block to produce the driving pulses applied to the $\overline{\mathrm{DC}} / \mathrm{DC}$ converter to control the DC motor.

Detailed information on how to build a hardware experiment using MATLAB Simulink and dSPACE can be found in [43]. Information about online processing capabilities of dSPACE DS1103 and its real-time coding specifications can be found in $[44,43]$. 
MATLAB

DC Motor

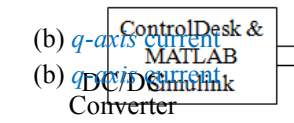

DC monverter

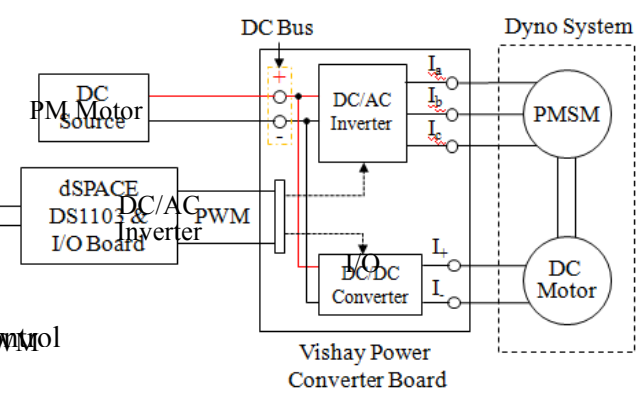

(a) Circuit connection

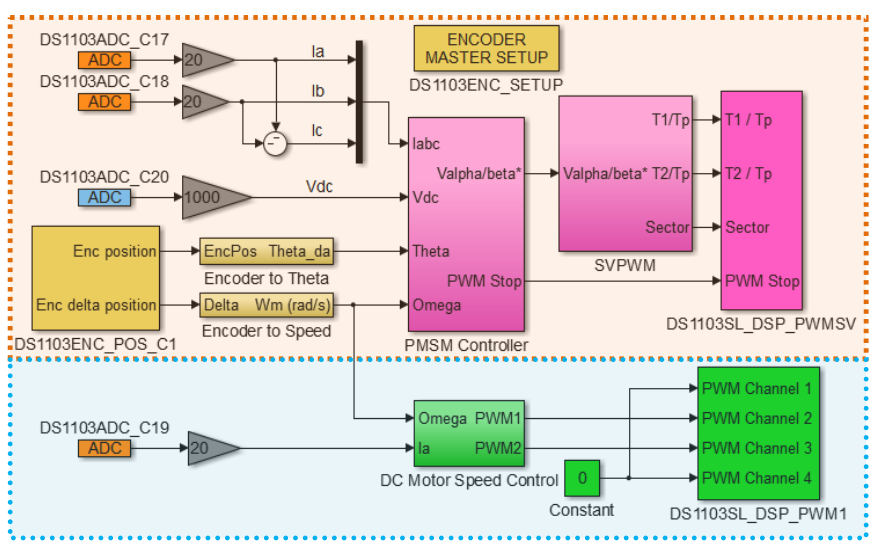

(b) dSPACE based real-time controller

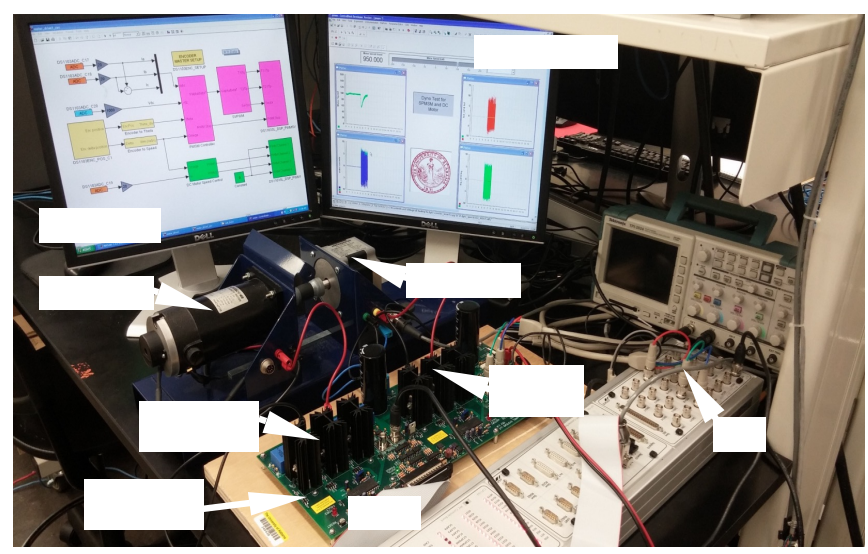

(c) Experiment setup

Fig. 13. Hardware laboratory testing and control systems

The simulation cases shown by Figs. 6 through 12 in Section V are divided into two categories: one corresponds to speed and current tracking control (Figs. 6, 8, 11 and 12), while the other corresponds to current tracking control only under constant motor speed (Figs. 7, 9 and 10). Then, hardware experiments were performed based on the laboratory setup for each of these cases, with Section VII-B showing the results associated with the speed and current tracking control and Section VII-C giving the results associated with current tracking under constant motor speed. The parameters of the laboratory motor are shown in Table I and the controller sampling rate is $0.1 \mathrm{~ms}$. The minimum rotational speed that can be measured using the speed sensor was found to be $1.31 \mathrm{rad} / \mathrm{s}$, or $12.5 \mathrm{rpm}$ in the experimental setup. In the experimental arrangement, the PM motor parameters could be different from the nominal values shown in Table I $[45,46]$ and there could be unexpected disturbances and noises.

\section{B. PM Motor Speed and Current Control}

In this test, both the speed and current controls are applied to the PM motor while the DC motor is idle. The speed- and current-loop controllers of the PM motor were redesigned based on the parameters shown in Table I, and were tested first in the simulation, and then on the hardware motor. The test sequence was scheduled as follows, with $\mathrm{t}=0 \mathrm{~s}$ as the starting point for data recording: At $\mathrm{t}=1 \mathrm{~s}$, the input speed increases from $0 \mathrm{rad} / \mathrm{s}$ to $100 \mathrm{rad} / \mathrm{s}$, and then stays at $100 \mathrm{rad} / \mathrm{s}$; at $\mathrm{t}=2 \mathrm{~s}$, the speed decreases to $50 \mathrm{rad} / \mathrm{s}$ and retains this value till $\mathrm{t}=3 \mathrm{~s}$; at $\mathrm{t}=3 \mathrm{~s}$, the speed increases to $200 \mathrm{rad} / \mathrm{s}$ and decreases again to $100 \mathrm{rad} / \mathrm{s}$ at $\mathrm{t}=4 \mathrm{~s}$.

Fig. 14 presents the simulation results. Due to the low ratings of the laboratory motor, the relevant oscillation of the simulated stator current looks worse than that of the $50 \mathrm{~kW}$ PM motor in tracking the current variation in a much larger range in Section VI. The result of the hardware experiment (Fig. 15) is a little bit different from the simulation result. A potential reason is that the actual motor inertia and friction coefficient are more complicated and different from those used in the simulation. Due to uncertain motor parameters, noises and disturbances, more oscillations of the PM motor were found in the hardware experiment results (Fig. 15). Under the challenging laboratory condition, the NN controller performed better than the conventional controller (Fig. 15).

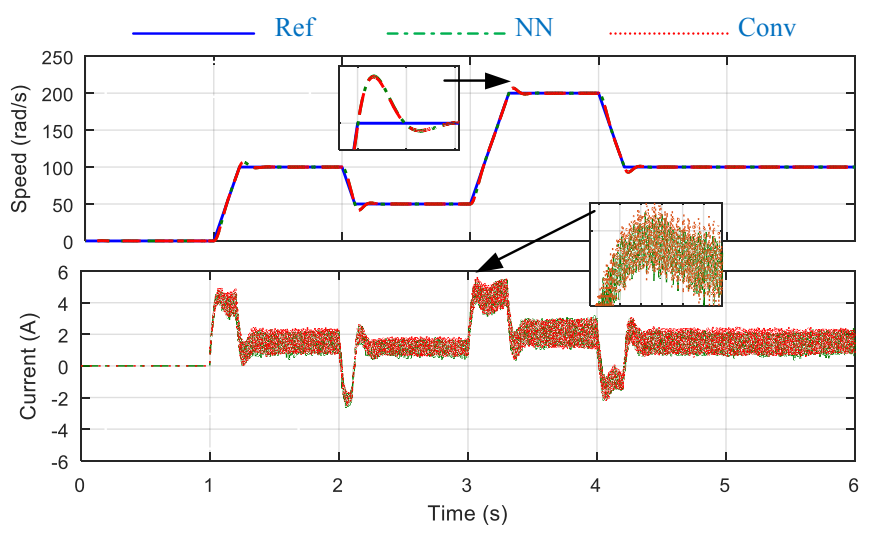

Fig. 14. NN vs. conventional: simulation of laboratory PM motor: (a) Reference and actual motor rotational speeds, (b) q-axis currents

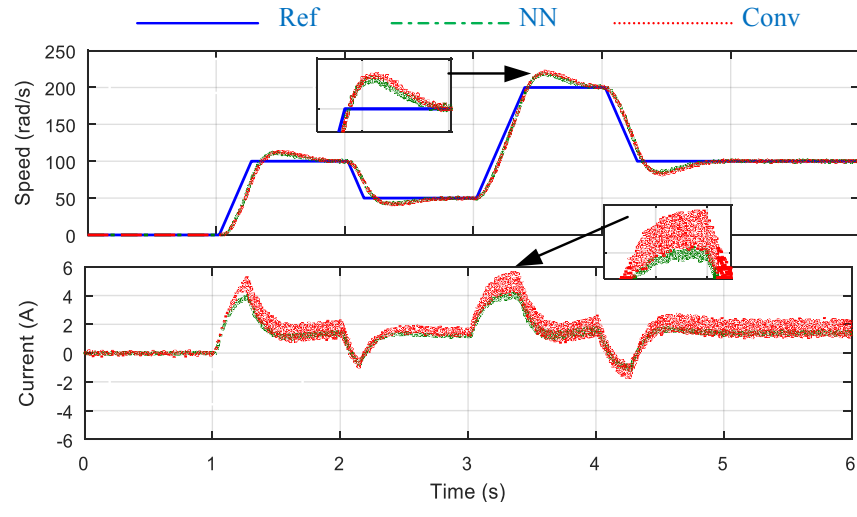

Fig. 15. NN vs. conventional: hardware experiment of laboratory PM motor: (a) Reference and actual motor rotational speeds, (b) q-axis currents

\section{PM Motor Current Control under Constant Speed}

In this case, only the current control is applied to the PM motor while the DC motor is controlled to ensure the speed of 
the whole system constant. Fig. 16a shows the simulation

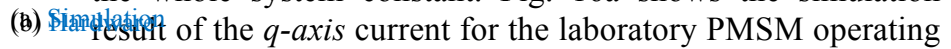
at $100 \mathrm{rad} / \mathrm{s}$ and zero $d$-axis reference current. Again, the much smaller current tracking range makes the relevant oscillation of the motor current apparently worse than that of the $50 \mathrm{~kW}$ PM motor shown in Section VI. Fig. 16b presents the hardware experiment results of the q-axis current under the same condition. The NN controller clearly displays less oscillation than the conventional controller for the laboratory PM motor, showing a strong adaptive control ability of the NN controller under uncertain, noisy and disturbing laboratory conditions. The success of the hardware experiments indicates that it is possible to implement the NN controller in a real-life PM motor.

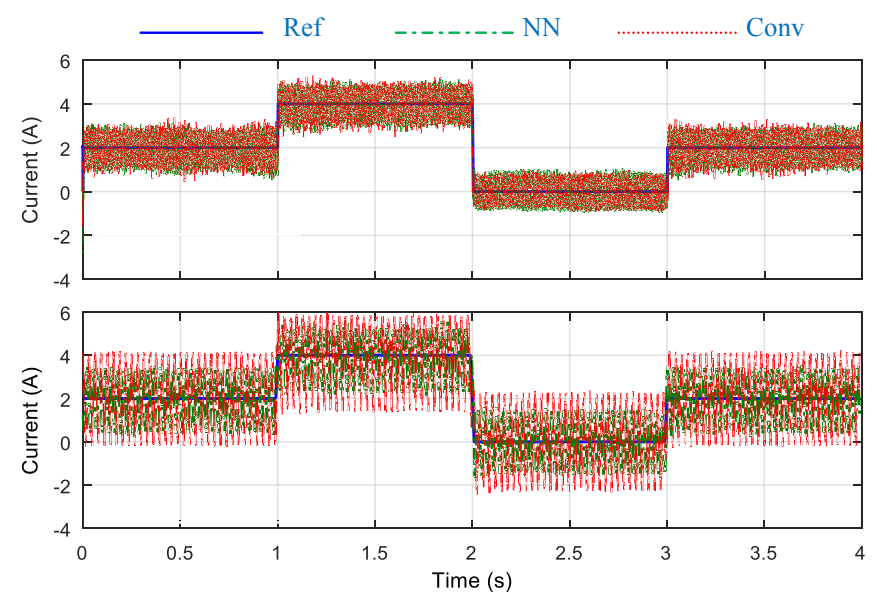

Fig. 16. NN vs. conventional: (a) simulated and (b) experiment q-axis current of laboratory PM motor

A summary in terms of maximum, average, and standard deviation of the absolute tracking errors associated with the experiment results shown by Figs. 15 and 16 for the NN and conventional controllers is presented in Table III.

TABLE II

TRACKING ERROR MAXIMUM, AVERAGE, AND STANDARD DEVIATION VALUES

\begin{tabular}{|c|c|c|c|c|c|c|}
\hline \multirow{2}{*}{ Figure \# } & \multicolumn{2}{|c|}{ Maximum } & \multicolumn{2}{c|}{ Average } & \multicolumn{2}{c|}{ Std } \\
\cline { 2 - 7 } & NN & Conv. & NN & Conv. & NN & Conv. \\
\hline $\begin{array}{c}\text { Speed tracking } \\
\text { Fig. 14(a) (rad/s) }\end{array}$ & 8.3859 & 8.5428 & 0.6709 & 0.6673 & 1.6791 & 1.6703 \\
\hline $\begin{array}{c}\text { Speed tracking } \\
\text { Fig. 15(a) (rad/s) }\end{array}$ & 32.7481 & 36.0681 & 5.2326 & 5.8308 & 7.1686 & 8.2316 \\
\hline $\begin{array}{c}\text { Current tracking } \\
\text { Fig. 16(a) (A) }\end{array}$ & 4.73 & 3.55 & 0.44 & 0.39 & 0.27 & 0.26 \\
\hline $\begin{array}{c}\text { Current tracking } \\
\text { Fig. 16(b) (A) }\end{array}$ & 1.90 & 3.48 & 0.82 & 0.94 & 0.41 & 0.64 \\
\hline
\end{tabular}

\section{CONCLUSION}

PMSMs are widely used in electric drive applications particularly in electric drive vehicles. This paper presents an NN-based vector-control method to overcome the limitations of conventional vector-control approaches. It describes how to achieve approximately optimal vector control using a neural network, which is trained to minimize an ADP-based cost function. Compared to the conventional vector control, the NN vector controller produces the fastest response speed, lowest overshoot, and, in general, the best performance. Additionally, since a neural network is trained under variable system parameters, the NN-based vector controller shows enhanced performance when the sampling time changes and system parameters are difficult to identify, especially in hardware experiment conditions. The hardware experiment confirmed that the NN-based controller is able to track reference commands while maintaining a high power quality, making it possible to implement the NN vector controller in a real PMSM environment. In hardware experimental conditions, a conventional controller usually needs to be retuned whenever the motor parameters change. In contrast, the NN-based controller retains good performance under a variety of runtime PM motor parameters, despite the NN being trained using the nominal motor parameters of Table 1 .

\section{REFERENCES}

[1] C. Lin, T. Liu, L, Fu, and C. Hsiao, "Model-free predictive current control for interior permanent-magnet synchronous motor drives based on current difference detection technique." IEEE Trans. Ind. Electron., 61, no. 2 (2014): 667-681.

[2] T. Türker, Umit Buyukkeles, and A. Faruk Bakan, "A Robust Predictive Current Controller for PMSM Drives." IEEE Trans. Ind. Electron., 63, no. 6 (2016): 3906-3914.

[3] Y. Ren, Z.Q. Zhu, and J. Liu, "Direct torque control of permanentmagnet synchronous machine drives with a simple duty ratio regulator." IEEE Trans. Ind. Electron., 61, no. 10 (2014): 5249-5258.

[4] Y. Cho, K. Lee, J. Song, and Y. Lee, "Torque-ripple minimization and fast dynamic scheme for torque predictive control of permanentmagnet synchronous motors." IEEE Trans. Power. Electron., 30, no. 4 (2015): 2182-2190.

[5] C. Xia, B. Ji, and Y. Yan, "Smooth Speed Control for Low-Speed High-Torque Permanent-Magnet Synchronous Motor Using Proportional-Integral-Resonant Controller," IEEE Trans. Ind. Electron., vol. 62(4), pp. 2123-2134, Apr. 2015.

[6] M. Qian, "Mixed H2/Hœ control of permanent magnet synchronous motor based on particle swarm optimization algorithm." Journal of Computer Applications, 8 (2012): 076.

[7] D. S. Bernstein and W. M. Haddad, "LQG control with an Hळ performance bound: a riccati equation approach," IEEE Trans. Autom. Control, vol. 34, no. 3, pp. 293-305, Mar. 1989.

[8] S. Das and I. Pan, "On the mixed $\mathrm{H} 2 / \mathrm{H} \infty$ loop-shaping tradeoffs in fractional-order control of the AVR system," IEEE Trans. Ind. Informat., vol. 10, no. 4, pp. 1982-1991, Nov. 2014.

[9] H. Zhang, Y. Shi, and A. S. Mehr, "Parameter-dependent mixed $\mathrm{H} 2 / \mathrm{H} \infty$ filtering for linear parameter-varying systems," IET Signal Processing, vol. 6, no. 7, pp. 697-703, Sep. 2012.

[10] H. Shayeghi, A. Jalili, and H. Shayanfar, "A robust mixed H2/Hळ based LFC of a deregulated power system including SMES," Energy Conversion and Management, vol. 49, no. 10, pp. 2656-2668, 2008.

[11] A.A. Stoorvogel, "The $\mathrm{H} \infty$ control problem: a state space approach," University of Michigan, Feb. 5, 2000, available at http://wwwhome.math.utwente.nl/ stoorvogelaa/book2.pdf.

[12] Z. Li, C. Zang, P. Zeng, H. Yu, S. Li and X. Fu, "Mixed H2/Hळ Optimal Control for Three-phase Grid Connected Converter," International Journal of Electronics. Status: in press.

[13] B. Akin and M. Bhardwaj, "Sensorless Field Oriented Control of 3Phase Permanent Magnet Synchronous Motors," Texas Instruments Incorporated. Available at

http://www.ti.com/lit/an/sprabq3/sprabq3.pdf.

[14] R. Filka and M. Stulrajter, "3-Phase PMSM Motor Control Kit with the MPC5604P," Freescale Semiconductor, Inc., available at https://cache.freescale.com/files/product/doc/AN1931.pdf.

[15] S. Li, T.A. Haskew, and L. Xu, "Conventional and Novel Control Designs for Direct Driven PMSG Wind Turbines," Electric Power Syst. Research, vol. 80, pp. 328-338, March 2010.

[16] M.A. Rahman, and M.A. Hoque, "On-line adaptive artificial neural network based vector control of permanent magnet synchronous motors." IEEE Trans. Energy Conv., 13, no. 4 (1998): 311-318.

[17] Y. Yi, D.M. Vilathgamuwa, and M.A. Rahman. "Implementation of an artificial-neural-network-based real-time adaptive controller for an 
interior permanent-magnet motor drive." IEEE Trans. Ind. Appl., 39, no. 1 (2003): 96-104.

[18] T. Pajchrowski, and K. Zawirski, "Application of artificial neural network to robust speed control of servodrive." IEEE Trans. Ind. Electron., 54, no. 1 (2007): 200-207.

[19] C. Xia, C. Guo, and T. Shi, "A neural-network-identifier and fuzzycontroller-based algorithm for dynamic decoupling control of permanent-magnet spherical motor." IEEE Trans. Ind. Electron., 57, no. 8 (2010): 2868-2878.

[20] Dimitri P. Bertsekas, " Dynamic Programming and Optimal Control: Approximate Dynamic Programming," 4th Ed., Athena Scientific, 2012.

[21] F.L. Lewis and D. Liu (eds.), Reinforcement Learning and Approximate Dynamic Programming for Feedback Control, IEEE Press / Wiley, 2012, pp. 474-493.

[22] H. Zhang, C. Li, X. Zhang, and Y. Luo, "Data-Driven Robust Approximate Optimal Tracking Control for Unknown General Nonlinear Systems Using Adaptive Dynamic Programming Method," IEEE Trans. Neural Netw., vol. 22, no. 12, pp. 2226-2236, Dec. 2011.

[23] G. Xiao, H. Zhang, Y. Luo, and Q. Qu, "General value iteration based reinforcement learning for solving optimal: tracking control problem of continuous-time affine nonlinear systems," Neurocomputing, vol. 245, pp. 114-123, 2017.

[24] Q. Wei, G. Shi, R. Song, and Y. Liu, "Adaptive Dynamic Programming-Based Optimal Control Scheme for Energy Storage Systems With Solar Renewable Energy," IEEE Trans. Ind. Electron. vol. 64, no. 7, pp. 5468-5478, Jul. 2017.

[25] Q. Wei, D. Liu, and G. Shi, "A Novel Dual Iterative Q-Learning Method for Optimal Battery Management in Smart Residential Environments," IEEE Trans. Ind. Electron., vol. 62, no. 4, pp. 25092518, Apr. 2015.

[26] Q. Wei, D. Liu, G. Shi, and Y. Liu, "Multibattery Optimal Coordination Control for Home Energy Management Systems via Distributed Iterative Adaptive Dynamic Programming," IEEE Trans. Ind. Electron., vol. 62, no. 7, pp. 4203-4214, Jul. 2015.

[27] S. Li, M. Fairbank, X. Fu, D.C. Wunsch, and E. Alonso, "Vector Control of Permanent Magnet Synchronous Motor using Adaptive Recurrent Neural Networks," Proc. 2013 IEEE International Joint Conference on Neural Network, Dallas USA, August 4-9, 2013.

[28] D.V. Prokhorov, L.A. Feldkamp, and I.Y. Tyukin. "Adaptive behavior with fixed weights in RNN: an overview," Proc. the IEEE Int. Joint Conf. on Neural Networks (IJCNN), pp. 2018-2023, 2002.

[29] N. Mohan, Advanced Electric Drives - Analysis, Modeling and Control using Simulink, MN: Minnesota Power Electronics Research \& Education, ISBN 0-9715292-0-5, 2001.

[30] S. Li, T.A. Haskew, E. Muljadi and C. Serrentino, "Characteristic Study of Vector-Controlled Direct Driven Permanent Magnet Synchronous Generator in Wind Power Generation," Electric Power Compon. and Syst., vol. 37, pp. 1162-1179, Oct. 2009.

[31] N. Mohan, T. M. Undeland, and W. P. Robbins, Power Electronics: Converters, Applications, and Design, $3^{\text {rd }}$ Ed., John Wiley \& Sons Inc., October 2002

[32] X. Fu, S. Li, M. Fairbank, D. C. Wunsch, and E. Alonso, "Training recurrent neural networks with the Levenberg-Marquardt algorithm for optimal control of a grid connected converter," IEEE Trans. Neural Netw. Learn. Syst., Oct. 2014.

[33] M.T. Hagan, H.B. Demuth, M.H. Beale, Neural Network Design; PWS Publishing: Boston, USA, 2002.

[34] F.Y. Wang, H. Zhang, and D. Liu, "Adaptive dynamic programming: An introduction," IEEE Comput. Intell. Mag., pp. 39-47, 2009.

[35] M. Fairbank, S. Li, X. Fu, E. Alonso, \& D. Wunsch, "An adaptive recurrent neural-network controller using a stabilization matrix and predictive inputs to solve a tracking problem under disturbances," Neural Networks, 49, pp. 74-86, 2014.

[36] M. Hagan and M. Menhaj, "Training feedforward networks with the marquardt algorithm," IEEE Trans. Neural Netw., vol. 5(6), pp. 989993, Nov. 1994.

[37] P. Werbos, "Backwards differentiation in AD and neural nets: Past links and new opportunities," Automatic differentiation: Applications, theory, and implementations, 15-34, Springer, Berlin, Heidelberg, 2006.

[38] L.B. Roll, "Automatic Differentiation Techniques and Applications," Lecture Notes in Computer Science 120, Edited by G. Goos and J. Hartmanis, Springer, 1981
[39] O. Tremblay and L.A. Dessaint, "Hybrid Electric Vehicle Power Train Using Battery Model," MATLAB 2010, The MathWorks, Inc.

[40] MotorSolver, "Permanent Magnet Brushless Motor (Fitted with 1000 line encoder) for DYNO-KITS used for Teaching Labs," The University of Minnesota.

[41] The MathWorks, "Model and simulate electrical power systems," available at https://www.mathworks.com/products/simpower.html.

[42] S. Haykin, "Neural Networks - A comprehensive foundation," Prentice Hall, 1999.

[43] A. Thomas, "dSPACE DS1103 Control Workstation Tutorial and DC Motor Speed Control," Senior Project Report, Bradley University ECE Department, May 11, 2009, available at http://ee.bradley.edu/projects/proj2009/dscntrl/Tutorial.pdf.

[44] "DS1103 PPC Controller Board," available at http://www.ceanet.com.au/Portals/0/documents/products/dSPACE/dsp ace_2008_ds1103_en_pi777.pdf

[45] S.J. Underwood and I. Husain, "Online parameter estimation and adaptive control of permanent-magnet synchronous machines," IEEE Trans. Ind. Electron., vol. 57, no. 7, pp.2435-2443, 2010.

[46] D. Yang, H. Mok, J. Lee, and S.Han. "Adaptive Torque Estimation for an IPMSM with Cross-Coupling and Parameter Variations," Energies, 10(2), (2017): 167. 